\title{
Atenção conjunta virtual e a construção da ação colaborativa
} Virtual joint attention and the construction of collaborative work

Doutor em Linguística pelo Programa de PósGraduaçáo em Linguistica da Universidade Federal da Paraiba. E professor adjunto IV do Instituto Federal da Paraiba, atuando principalmente no Coordena o Núcleo de Estudos em Aquisicãoa da Linguagem e Ensino (NEALE), por meio do qual desenvolve projetos de iniciação científica com estudantes de Letras. E-mail: jmscostafilho@gmail.com

Doutora em Linguistica pela Unicamp. É professora (UFPB), vinculado ao Departamento de Latras Clássicas e Vernáculas e ao Programa de PósGraduação em Linguística. E também bolsista de produtividade do CNPq e coordenadora do Laboratório de Aquisição da Fala e da Escrita

E-mel: marin
RESUMO: 0 objetivo deste artigo é discutir a noção de atenção conjunta virtual e a construção da ação colaborativa nesse processo. Para tanto, analisamos dados de vinte crianças, de 22 a 65 meses de idade, jogando com o aplicativo Mimi $^{\circledR}$. Esse jogo foi desenvolvido para tablets e é composto por dez fases em que a criança é convidada a cumprir tarefas para cuidar de um gato, por meio de instruções fornecidas pelo narrador do jogo, presente na realidade virtual. A discussão proposta neste artigo tem como base a teoria da atenção conjunta, discutida principalmente por Bruner (1975) e Tomasello (2003), e a noção de ação colaborativa trazida por Tomasello e Carpenter (2007). Já o conceito de atenção conjunta virtual (COSTA FILHO, 2016) se constitui quando a criança interage com o narrador presente na realidade virtual. Esse processo modificado de atenção conjunta, no entanto, também requer a ação colaborativa que, como mostram os dados, envolve tanto interlocutores da realidade atual quanto da realidade virtual. Os dados mostram ainda que as crianças mais novas têm mais dificuldade para estabelecer a atenção conjunta virtual e que, por isso, buscam com mais frequência o interlocutor atual para a ação colaborativa.

Palavras-chave: Atenção conjunta virtual; Ação colaborativa; Realidade virtual.

ABSTRACT: The aim of this paper is to discuss the notion of virtual joint attention and the construction of the collaborative work within this process We analyze data of twenty children, ranging from 22 to 65 months old, playing with the application Mimi(C). This game was designed for tablets and it is composed of ten stages in which the child is invited to perform tasks in order to take care of a kitten, through instructions given by the narrator in the virtual reality. The discussion proposed in this paper is based on the theory of joint attention, mainly studied by Bruner (1975) and Tomasello (2003), and the notion of collaborative work discussed by Carpenter and Tomasello (2007). The concept of virtual joint attention (COSTA FILHO 2016) is constituted when the child interacts with the narrator in the virtual reality. This modified process of joint attention, however, also requires the collaborative work that, as data show, involves both interlocutors in the current reality and in the virtual one. The data also show that it is more difficult to younger children to establish the virtual joint attention and that, for this reason, they search for the current interlocutor more often.

Keywords: Virtual joint attention; Collaborative work; Virtual reality. 


\section{Introdução e os princípios teóricos da atenção conjunta}

processo de atenção conjunta é um tema que permeia os estudos relacionados à cognição desde meados da década de 1970, perpassando não somente a área de Linguística, mas também Psicologia e Antropologia (MIGUENS, 2006). Em Linguística, a atenção conjunta se aproxima dos estudos voltados para a Aquisição da Linguagem, quando vista sob um viés interacionista e multimodal, isto é, em pesquisas que observam a linguagem infantil como um dado inserido na interação social com os adultos que cercam a criança e contemplando as produções verbais em paralelo com o não verbal, marcado especialmente por gestos e pela própria atenção conjunta. Essas pesquisas podem contemplar desde a aquisição inicial até a aquisição da referência linguística, panorama no qual se inserem as crianças com mais de dois anos.

Bruner (1975) é um dos primeiros teóricos a discutir a teoria da atenção conjunta. Partindo da ideia de que as crianças se inserem em trocas interativas com os adultos que a cercam desde o nascimento, o autor traz o conceito de atenção conjunta como uma ação que se constrói sob um formato triangular que envolve adulto, criança e um objeto qualquer. Ainda para o referido teórico, a atenção conjunta é uma das estratégias das quais o infante faz uso para garantir seu lugar na interação, tendo em vista que não domina a linguagem verbal.

Outro pesquisador cujos trabalhos sobre a teoria da atenção conjunta se destacam é Tomasello (2003). Partindo das considerações de Bruner, Tomasello (2003) trata a atenção conjunta como um processo triádico, diferentemente das primeiras interações diádicas da criança - como, por exemplo, o face a face estabelecido entre o bebê e a mãe. 0 autor traz, então, a noção de cenas de atenção conjunta como "interações sociais nas quais a criança e o adulto prestam conjuntamente atenção a uma terceira coisa, e à atenção um do outro à terceira coisa, por um período razoável" (TOMASELLO, 2003, p.135).

Tomasello (2003) situa a atenção conjunta num período de intenso desenvolvimento cognitivo infantil chamado de "revolução dos nove meses". Esse período corresponde a uma fase do desenvolvimento infantil em que a criança passa por uma espécie de "explosão" cognitiva que modifica a forma como ela enxerga a si, ao outro e ao mundo que a rodeia, em outras palavras, os três pilares da atenção conjunta.

A compreensão pela criança de si, do outro e do que a rodeia, no entanto, não é o único requisito para as ocorrências da interação de atenção conjunta, conforme trazemos de autores como Eilan (2005), Peacocke (2005) e Gómez (2005). Regular, manter e reconhecer a atenção entre o parceiro na troca interativa e o objeto ao qual presta atenção juntamente com o outro requer da criança outra habilidade: a compreensão da intencionalidade e, consequentemente, do outro como um agente intencional. Essa é a perspectiva de Tomasello (2003) quando defende que, dentro do período denominado "revolução dos nove meses", a criança passa a reconhecer o seu interlocutor como agente intencional.

Debruçando-se sobre a noção de intencionalidade compartilhada, Tomasello e Carpenter (2007) dizem que esta noção "se refere a interações colaborativas em que os participantes compartilham estados psicológicos entre si" ${ }^{1}$. Nessa direção, os autores apontam que a intencionalidade compartilhada age sobre quatro habilidades já adquiridas pelas crianças.

A primeira refere-se à "habilidade de acompanhamento do olhar e atenção conjunta"2 e diz respeito à capacidade que a criança demonstra de, reconhecendo a existência do outro, perceber seu olhar e compartilhar com

${ }^{1}$ Tradução nossa para "[...] refers to collaborative interactions in which participants share psychological

2 Tradução nossa para "gaze following and joint attention" (TOMASELLO \& CARPENTER, 2007, p. 121). 
ele desse mesmo ponto de atenção. Nessa primeira habilidade está inserida a transição entre o olhar compartilhado - dois sujeitos olhando fixamente para um mesmo elemento externo - e "a atenção conjunta plena"3 (PEACOCKE, 2005, p.298), em que ambos os participantes compreendem que têm a atenção voltada a um elemento externo em comum.

A segunda habilidade, "manipulação social e comunicação cooperativa"4, é representada pelos gestos utilizados pela criança com a intenção de se comunicar, sendo estes controlados pela motivação e pela intencionalidade compartilhada (MELO, 2015). Ou seja, a criança não utiliza os gestos aleatoriamente, mas sim a partir de sua intenção na troca interativa.

A habilidade de "atividade de grupo e colaboração"5 é a terceira das que são apontadas por Tomasello e Carpenter (2007) e corresponde à capacidade de colaboração entre os parceiros inseridos em uma troca interativa em que ambos têm um mesmo objetivo e executam ações conjuntamente para alcançá-lo. Nessa habilidade, a intencionalidade está presente no momento em que, dentro da atenção conjunta, os sujeitos traçam uma espécie de plano para atingir a meta que compartilham. Traçar um plano, entretanto, não é uma ação literal que poderíamos compreender como a elaboração de uma estratégia, mas sim uma marca do envolvimento dos sujeitos que partilham um determinado objetivo.

As noções de "aprendizagem social e aprendizagem instruída"6 representam a quarta habilidade discutida em Tomasello e Carpenter (2007). Conforme apontam os teóricos, a aprendizagem social possui, paradoxalmente, um caráter individual, visto que as crianças "recolhem informações unilateralmente [...] dos adultos nos quais confiam"7 (TOMASELLO

3 Refere-se à tradução nossa para o conceito de "full joint attention".

4 Tradução nossa para "social manipulation and cooperative communication" (TOMASELLO e CARPENTER, 2007, p. 122).

5 Tradução nossa para "group activity and collaboration" (TOMASELLO e CARPENTER, 2007, p.123).

6 Tradução nossa para "social learning and instructed learning" (TOMASELLO e CARPENTER, 2007, p. 121).

7 Tradução nossa para "[...] gather information unilaterally [...] from unsuspecting adults". e CARPENTER, 2007, p.123). Já a aprendizagem instruída refere-se às situações de interação nas quais os adultos ensinam algo às crianças por meio de demonstração. Ambas as formas de aprendizagem inserem-se na intencionalidade compartilhada quando as crianças recorrem à imitação do que foi aprendido não apenas motivadas pelo objetivo de desempenhar a ação, mas também para mostrar ao adulto o que aprenderam.

É, no entanto, sobre a terceira habilidade que nos debruçaremos ao observar os dados que serão apresentados a seguir para a discussão no presente artigo, com o objetivo de discutir a noção de atenção conjunta virtual e a construção da ação colaborativa nesse processo.

\section{Dos princípios metodológicos à atenção conjunta virtual}

A interação de atenção conjunta que discutiremos a partir desde ponto é fruto das inovações tecnológicas que permitem que sujeitos interajam a partir de espaços distintos. Tendo como base a atenção conjunta em seu formato atual ${ }^{8}$, a configuração de atenção conjunta a qual demos o nome de atenção conjunta virtual ${ }^{9}$ diferencia-se do primeiro formato porque acontece entre sujeitos que interagem a partir de espaços distintos.

Para exemplificar a atenção conjunta virtual, pensemos nos dados que serão expostos neste trabalho, em que a criança interage com um interlocutor virtual presente em um jogo para tablets. Tais dados foram coletados com vinte crianças, de 22 a 65 meses de idade e organizadas em três grupos com base na faixa etária: grupo A ( 22 a 36 meses), grupo B ( 37 a 51 meses) e grupo C (52 a 65 meses). Os dados, cuja coleta foi aprovada por meio do

${ }^{8}$ A noção de atual e virtual apresentadas no presente trabalho são trazidas de Lévy (2011) e aprofundadas em Costa Filho (2016).

9 A atenção conjunta na realidade virtual é um tema recente na literatura. Contemplamos este tema na tese de Doutorado intitulada "Atenção conjunta: o jogo da referência na realidade virtual" (COSTA FILHO, 2016), da qual extraímos um recorte para o presente trabalho. 
Protocolo no 0509/2015 do Comitê de Ética em Pesquisa do Centro de Ciências da Saúde da Universidade Federal da Paraíba, foram coletados em uma escola privada da cidade de João Pessoa, na Paraíba, onde as crianças participantes estão matriculadas em séries da Educação Infantil.

Na situação da coleta estavam presentes o pesquisador e uma professora da escola e, individualmente, cada criança foi convidada a jogar duas vezes com o jogo Mimi ${ }^{\oplus 10}$. Esse jogo possui dez fases, nas quais o jogador precisa executar tarefas, descritas no Quadro 1, para ajudar um personagem humano a cuidar do gatinho Mimi, tendo um narrador como mediador da interação. A interação das crianças com o jogo foi gravada por meio de duas câmeras, uma captando o ambiente e a outra captando a tela do tablet durante os movimentos da criança para cumprir as tarefas do jogo.

Quadro 1 - Fases e suas respectivas tarefas

\begin{tabular}{|c|l|}
\hline Fase & \multicolumn{1}{|c|}{ Tarefa } \\
\hline 1 & Levar Mimi para o personagem humano. \\
\hline 2 & Levar Mimi, que se escondeu por trás da poltrona, para o personagem humano. \\
\hline 3 & Levar o leite para o personagem humano. \\
\hline 4 & Levar a tigela de Mimi para o personagem humano. \\
\hline 5 & Levar a tigela com leite para Mimi. \\
\hline 6 & Levar a tigela com ração para Mimi. \\
\hline 7 & Levar a bola para Mimi. \\
\hline 8 & Levar Mimi para a caminha. \\
\hline 9 & Levar Mimi, que está preso no armário, de volta para o tapete. \\
\hline 10 & Levar Mimi para o personagem humano, que retorna ao cenário. \\
\hline
\end{tabular}

Fonte: Costa Filho (2016, p.180).

${ }^{10} \mathrm{O}$ aplicativo foi desenvolvido para sistema Android por um grupo multidisciplinar formado por pesquisadores de Linguística, de Análise e Desenvolvimento de Sistemas para a Internet e de Design Gráfico. O grupo, integrante do LAFE (Laboratório de Aquisição da Fala e da Escrita) da UFPB, teve apoio financeiro do CNPq por meio do processo 371998/2014-0, dentro do edital 84/2013 para Núcleos Nascentes em Tecnologia Assistida do Programa das Tecnologias Educacionais e Sociais, tendo em vista a possibilidade de uso deste aplicativo como recurso para estudos com crianças com diagnóstico de patologias, principalmente como Transtorno e Déficit de Atenção e Hiperatividade (TDAH).
Todas as análises referentes aos dados que trazemos neste trabalho foram realizadas de modo a caracterizar o estudo como quali-quantitativo, já que procedemos com a contabilização das ocorrências dos fenômenos observados, e, ao mesmo tempo, selecionamos dados para salientar e ilustrar as trocas interativas de atenção conjunta.

Figura 1 - Tela inicial do jogo $\mathrm{Mimi}^{\odot}$

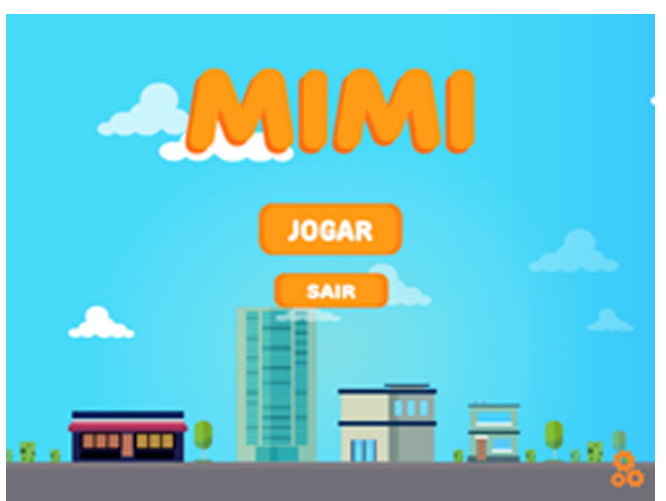

Fonte: Jogo Mimi@

Figura 2 - Gato Mimi

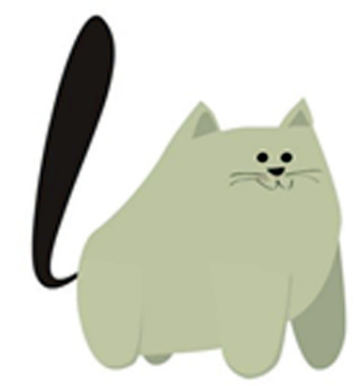

Fonte: Costa Filho (2016, p. 74) 
As Figuras 1 e 2 ilustram o jogo $\mathrm{Mimi}^{\circledR}{ }^{\complement}$, componente fundamental para a coleta dos dados, conforme mencionamos anteriormente. Sobre o jogo, é importante destacar ainda o lugar do narrador. Representado apenas por uma voz feminina, este integrante tem o conhecimento total das ações propostas e desempenhadas ao longo do jogo $\mathrm{Mimi}^{\circledR}$. Cabe ao narrador o lugar do adulto no contexto do aplicativo e, por assim ser, sua tarefa é explicar as situações, dar pistas, introduzir os comandos, dar o retorno sobre o acerto ou o erro do jogador, como se estivesse guiando o usuário em seu "passeio" pelas fases de Mimi ${ }^{\circ}$. A esse narrador pertence um espaço privilegiado, do qual ele observa as ações do jogo e media toda a interação que possa existir entre o usuário e os componentes do jogo. No entanto, como sua atuação é assíncrona em relação à ação do usuário, diferentemente do que acontece na interação entre adultos e crianças na vida cotidiana, os comandos do narrador são previsíveis e não podem ser reconstruídos na medida em que o jogo ocorre para melhor auxiliar seus usuários frente às dificuldades de execução das tarefas.

Partindo exatamente da relação assíncrona que se estabelece entre a criança e seu interlocutor virtual e no processo de atenção conjunta virtual constituído entre estes sujeitos, retornamos neste momento às habilidades (TOMASELLO; CARPENTER, 2007) sobre as quais a intencionalidade compartilhada presente na atenção conjunta age, conforme listado em Costa Filho (2016). A primeira habilidade, acompanhamento do olhar e atenção conjunta, demonstra-se quando a criança olha para a tela do tablet e, em seguida, acompanha com o olhar os direcionamentos do jogo dados pelo narrador, culminando no estabelecimento da atenção conjunta. Já a segunda habilidade, manipulação social e comunicação cooperativa, é representada pelo gesto de touch, uma forma de apontar na realidade virtual para movimentar o objeto foco da atenção conjunta e cumprir as tarefas do jogo. Uma vez estabelecida a atenção conjunta virtual da criança com o jogo, a atividade de grupo e colaboração acontece envolvendo criança, narrador e personagens no momento em que "o usuário interage com o narrador, que media a colaboração entre criança e personagem [...], com o objetivo de cuidar do gatinho" (COSTA FILHO, 2016, p. 155). A aprendizagem social e a aprendizagem instruída, por sua vez, estão relacionadas, respectivamente, ao conhecimento prévio que as crianças participantes da pesquisa detêm sobre como utilizar o tablet, o que permite as ações durante o jogo, e à compreensão dos comandos que instruem a criança sobre o que fazer e como fazer para cumprir a tarefa requisitada pelo narrador.

Em qualquer uma das habilidades está presente a ideia de que a atenção conjunta atual serve de base para a constituição do formato virtual dessa interação. Entretanto, a atenção conjunta atual é especialmente destacada na atividade de grupo e colaboração, quando observamos o papel da professora que acompanhou as crianças no momento em que elas jogaram com Mimi ${ }^{\odot}$, tornando-se um possível interlocutor atual para as crianças em atenção conjunta com o jogo.

A seguir, veremos com base nos dados, como ocorreu a atuação desse interlocutor atual e as implicações desta atuação para a atenção conjunta virtual.

\section{Ação colaborativa e atenção conjunta virtual}

Quando se coloca em meio à estrutura interativa da atenção conjunta virtual, a professora não parece ter a intenção de atrair o olhar da criança e participar do jogo em questão. No entanto, por estar presente nas sessões de coleta dos dados, ela acaba se colocando como um possível interlocutor dentro da situação, principalmente se considerarmos o fato de que o narrador do jogo $\mathrm{Mimi}^{\circledR}$, que representa o adulto na interação virtual, tem sua participação assíncrona em relação à criança, já que sua fala está pronta 
e programada dentro do aplicativo, não sendo possível que este narrador reformule seu texto frente às possíveis dificuldades dos jogadores.

Dois pontos se destacam na busca da criança pelo interlocutor situado no espaço atual, ou seja, o mesmo espaço em que está a criança. 0 primeiro remete ao fato de que o formato da atenção conjunta atual lhe é mais comum e estabilizado, já que desde antes do primeiro aniversário as crianças tendem a se engajar em atenção conjunta com os adultos que a cercam, sendo este um processo primordial para a aquisição da linguagem. O segundo, por sua vez, é a possibilidade de ação síncrona que o interlocutor atual possui, algo que foi observado nos dados no momento em que as crianças buscaram a professora para instruí-las como executar alguma tarefa proposta pelo narrador, interlocutor virtual.

Analisando os dados a partir do estabelecimento da atenção conjunta virtual, ou seja, considerando como ocorrências deste processo virtual os momentos em que as crianças cumpriam as tarefas de cada fase do jogo, pudemos constatar que a necessidade de instruções pela professora pode ser causada: i) pela falta de atenção da criança ao comando do narrador; ii) pelas situações nas quais, embora preste atenção, a criança não consegue executar o comando; ou ainda iii) pela falta de interação entre criança e narrador, chegando o usuário a ignorar os comandos fornecidos pelo interlocutor virtual. Os três motivos que apresentamos estão relacionados ao momento que antecede a execução da tarefa proposta no jogo, o que torna o processo de atenção conjunta atual com a professora responsável pelo cumprimento da tarefa, caso a criança consiga realizar a ação proposta na fase após ter recebido as instruções do interlocutor atual. Desse modo, a ação colaborativa, que na atenção conjunta virtual é realizada entre criança, narrador e personagens, passa a ser exercida também pela professora.

Com base nessa nova configuração de ação colaborativa percebemos dois modelos de atenção conjunta no que se refere à atuação da professora.
O primeiro é a atenção conjunta atual (AC atual) em seu formato simples, em que a interação da criança com o jogo Mimi está restrita à execução da tarefa. O segundo, a atenção conjunta composicional (AC composicional), tem a interação com a professora como fato que auxilia a atenção conjunta virtual a se estabelecer entre a criança e o jogo, servindo como uma base para que o formato virtual se consolide.

Os modelos ou formatos de AC atual e AC composicional estão ilustrados a seguir por meio de dois exemplos.

\section{Figura 3 - Exemplo 1: AC atual}

CRIANÇA 1 - 38 meses - Grupo B
FASE 1 - Jogada 1
Finalizado o comando do narrador, passam-se 4 segundos...
Criança: olha para a professora (começando a interação de atenção conjunta atual).
Professora: "Mimi é o gatinho (aponta para o gato) e Lila é a amiguinha. Você vai
ter que levar ele para passear até perto da amiguinha". Pausa de 5 segundos
Criança: desvia o olhar da professora para a tela e toca o gato sem realizar a
tarefa.
Professora: "Pega Mimi. Cadê Mimi? Mimi é o gato. Bote ele perto da amiguinha”.
Criança: cumpre a tarefa.

Fonte: Costa Filho (2016, p. 159).

A Figura 3 ilustra a $\mathrm{AC}$ atual. Vemos que a criança não apresenta reação ao comando do narrador, ou seja, não estabelece atenção conjunta virtual com o jogo $\mathrm{Mimi}^{\circledR}$. Em seguida, conforme mostra a transcrição, a criança dirige o olhar à professora, tomando-a como interlocutor na realidade atual $\mathrm{e}$ estabelecendo com ela a atenção conjunta. A professora, por sua vez, entra na ação colaborativa e fornece instruções que vão além do que o narrador tinha fornecido do ponto de vista virtual. Essas instruções síncronas permitem que a criança volte a atenção ao jogo e cumpra a ação. Fica evidente que sem 
a ação colaborativa do interlocutor atual a criança não teria executado a tarefa, pois a atenção conjunta virtual com o narrador não fora previamente estabelecida.

Vejamos o segundo exemplo:

Figura 4 - Exemplo 2: AC composicional

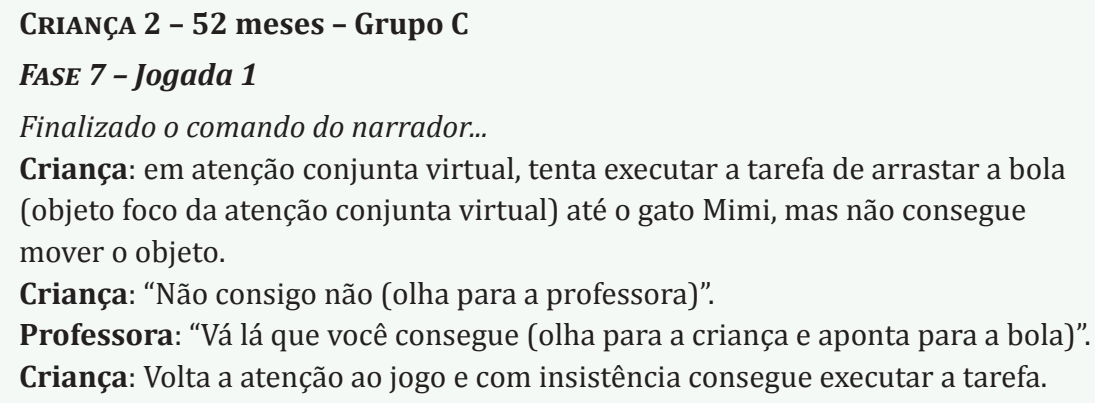

Finalizado o comando do narrador...

Criança: em atenção conjunta virtual, tenta executar a tarefa de arrastar a bola (objeto foco da atenção conjunta virtual) até o gato Mimi, mas não consegue mover o objeto.

Criança: "Não consigo não (olha para a professora)".

Professora: "Vá lá que você consegue (olha para a criança e aponta para a bola)". Criança: Volta a atenção ao jogo e com insistência consegue executar a tarefa.

Fonte: Costa Filho (2016, p. 160)

Já a Figura 4 destaca a AC composicional. Nesse exemplo, diferentemente do que acontece no exemplo da Fig. 3, percebemos que desde o início do recorte a criança 2 está em atenção conjunta virtual, acompanhando o comando do narrador e reagindo a este. Somente devido à dificuldade de movimentar o objeto foco da cena de atenção conjunta virtual, a criança, já inserida na atividade colaborativa com seu interlocutor virtual, busca a professora como interlocutor na realidade atual. Nesse momento, forma-se a AC composicional, um processo interativo que não necessariamente é o responsável pela execução da tarefa, mas que acompanha, ancorando e/ou complementando, o estabelecimento da atenção conjunta virtual.

$\mathrm{Na}$ AC composicional, a criança estabelece a ação colaborativa tanto com a professora quanto com o narrador, o que deixa esse formato mais amplo do que o formato de AC atual. A AC composicional, além de servir de base para a entrada da criança na interação com o jogo na realidade virtual, também é um modelo no qual a criança se engaja para checar com a professora seu desempenho após a finalização das tarefas propostas no jogo.

Após discutirmos brevemente alguns aspectos que compõem os dois formatos por meio do qual a ação colaborativa se desenvolve entre os interlocutores da criança nas realidades atual e virtual, apresentaremos a seguir, em gráficos, a quantidade identificada de ocorrências de cada formato ao longo das dez fases do jogo, começando pelo Gráfico 1 que segue.

Gráfico 1 - Ocorrências de atenção conjunta com o interlocutor atual (por crianças)

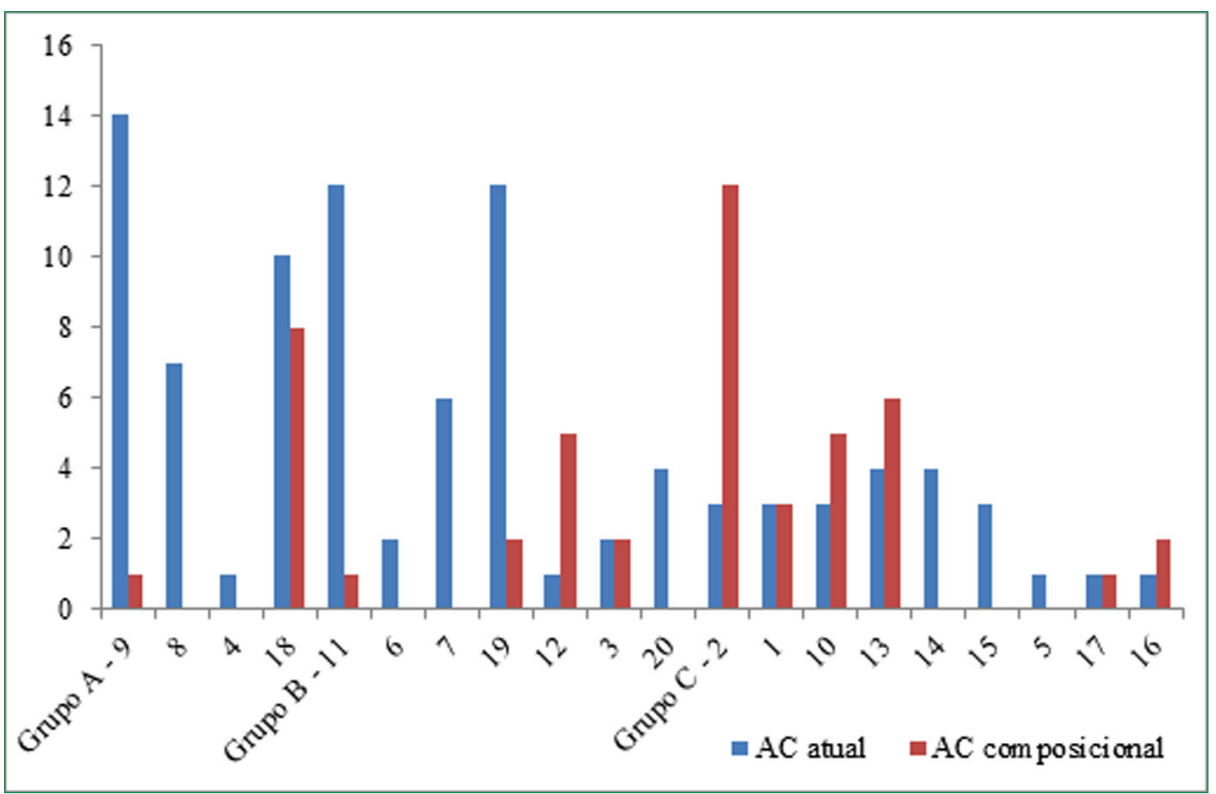

Fonte: Costa Filho (2016, p. 165). 
O Gráfico 1 mostra a quantidade de ocorrências por crianças dos grupos A, B e C - apresentadas em ordem crescente de idade da esquerda para a direita -, de cenas de atenção conjunta em que a criança busca a professora como interlocutor na realidade atual. Trazendo os índices gerais de cada criança divididos pelos tipos de atenção conjunta com a participação da professora, o gráfico evidencia que as crianças mais novas apresentam uma quantidade maior de cenas de atenção conjunta com o interlocutor atual. A criança 9, inclusive, a mais nova entre os participantes e integrante do grupo $\mathrm{A}$, é quem demonstra o maior índice de AC atual, em que interage apenas com a professora. No entanto, essa mesma criança, ainda que minimamente, apresenta AC composicional, na qual já é possível notar a interação com a realidade virtual, mesmo que embasada numa cena de atenção conjunta com o interlocutor atual, sustentando a ideia trazida por Costa Filho (2016) de que a AC atual serve de base para a AC virtual, a partir da noção de andaimes (WOOD; BRUNER; ROSS, 1976), em que durante o desenvolvimento cognitivo um processo dá sustentação ao seguinte, cuja complexidade é maior.

Considerando a funcionalidade que cada um dos tipos de atenção conjunta com o interlocutor atual exerce, não parece ser aleatório o fato de que as crianças menores desenvolvem mais AC atual do que AC composicional. Ao contrário, vemos como possível justificativa a necessidade que as crianças mais novas apresentam de receber comandos mais detalhados que aqueles trazidos pelo narrador. Logo, o formato de atenção conjunta atual em que a criança busca a professora para a interação serve ao propósito de facilitar a atuação da criança frente ao jogo.

A AC atual com a professora também se mostra mais viável e ganha relevância, pensando no papel que o interlocutor atual exerce de instruir a criança, porque a professora ocupa um lugar no espaço que a permite atuar de forma síncrona com a criança, ao contrário do narrador que age de forma assíncrona.
O Gráfico 1 mostra ainda que todas as crianças se engajaram em episódios de atenção conjunta com a professora do ponto de vista atual. Já o formato composicional, em que a atenção conjunta se constitui envolvendo a professora e também o interlocutor virtual, foi percebido nos dados de apenas doze das crianças que compõem o total de participantes. Desse modo, a quantidade de atenção conjunta atual em comparação à composicional parece estar associada ao fato de que aquele formato, destacado por Bruner (1983) e Tomasello (2003) como parte das interações infantis desde o primeiro ano de vida, já está mais estabilizado na rotina das crianças, mesmo das mais novas, enquanto este apresenta a interação com a realidade virtual como algo que ainda não é estável. Essa ausência de estabilidade da atenção conjunta com o interlocutor virtual de $\mathrm{Mimi}^{\circledR}$ pode estar associada também ao fato de que os dados representam a primeira vez que as crianças tiveram acesso ao jogo $\mathrm{Mimi}^{\odot}$, e a interação com o interlocutor virtual, que ocupa uma posição assíncrona em relação a elas, exige um grau de envolvimento maior com o jogo.

Seguindo a ideia de que o narrador é um interlocutor assíncrono e a professora ocupa um lugar síncrono em relação à criança, é possível observar que a professora, enquanto sujeito adulto que instrui a criança sobre como jogar ou confirma com a criança a realização da tarefa proposta pelo jogo, ocupa, na realidade atual, o espaço do narrador. A professora não é necessariamente um novo sujeito no contexto da interação, mas sim a transposição do sujeito previsto pelo jogo (narrador).

Para continuarmos as observações sobre as ocorrências das cenas de atenção conjunta atual e composicional, apresentaremos os Gráficos 2 e 3, que mostram como estes dois formatos de atenção conjunta ocorrem ao longo das fases (F) do jogo $\mathrm{Mimi}^{\odot}$. Consideraremos, agora, os sujeitos a partir de seus grupos. 
Gráfico 2 - Ocorrências de AC atual

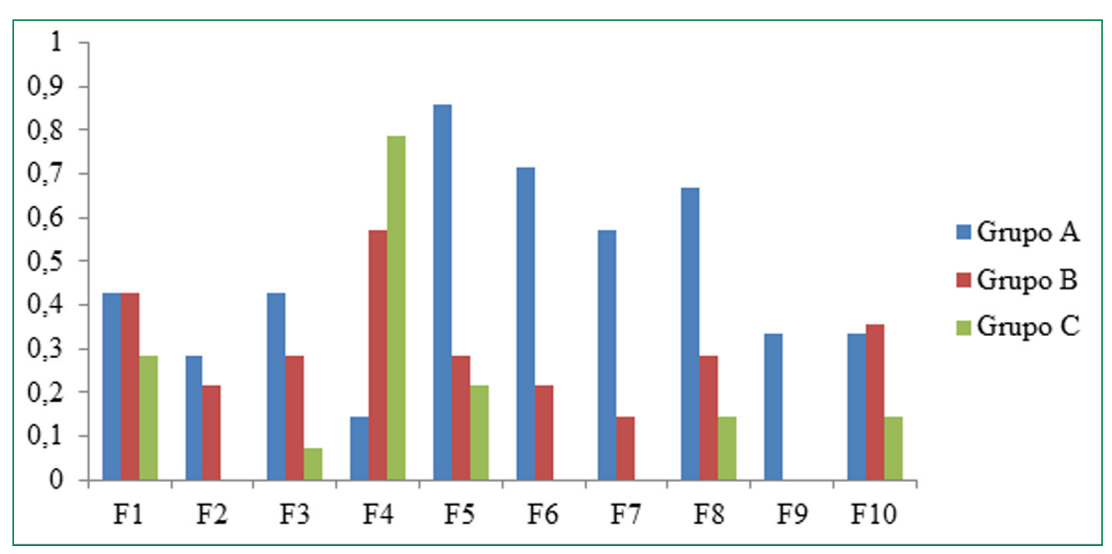

Fonte: Costa Filho (2016, p.167).

Com o Gráfico 2, notamos que apenas o grupo A apresenta AC atual durante todas as fases. Sendo seguido pelo grupo B, que apresenta em nove fases e, por fim, o grupo C que apresenta apenas em seis fases do jogo. Mais uma vez, portanto, o fator idade das crianças que compõem os grupos parece influenciar na composição da atenção conjunta com a professora durante o momento em que as crianças jogaram com $\mathrm{Mimi}^{\odot}$.

Sabendo que o modelo de AC atual é buscado pela criança principalmente como forma de adquirir instrução para cumprir as tarefas propostas no jogo, podemos notar que as crianças mais novas necessitam mais da intervenção da professora para que possam realizar as ações em $\mathrm{Mimi}^{\oplus}$. A quantidade de crianças que apresentam AC atual por fases também é proporcionalmente maior entre as crianças do grupo A. Ou seja, as crianças desse grupo não apenas apresentam $\mathrm{AC}$ atual em todas as fases, mas também em maior índice proporcional em relação às crianças dos grupos $\mathrm{B}$ e $\mathrm{C}$.

Esse índice muda apenas em dois momentos, nas fases 4 e 10. Observando o número de ocorrências de atenção conjunta atual entre as crianças e a professora na fase 10, percebemos que o grupo B supera o número apresentado pelo grupo $\mathrm{A}$, ainda que muito sutilmente. No entanto, é na fase 4 que percebemos uma mudança total de comportamento em relação ao índice de atenção conjunta atual. 0 dado que se mantém como padrão mais geral nas demais fases, ou seja, o grupo A com um número maior de ocorrências de $\mathrm{AC}$ atual com a professora e o grupo $\mathrm{C}$ com um número menor, inverte-se e o número de cenas de $\mathrm{AC}$ atual é maior entre as crianças do grupo C. Essa mudança no quantitativo de $\mathrm{AC}$ atual entre os grupos $\mathrm{A}$ e $\mathrm{C}$ pode estar relacionada à complexidade da fase 4 , um momento em que as crianças do grupo C, já engajadas e de certo modo com mais autonomia frente às tarefas do jogo, são surpreendidas com uma tarefa mais difícil que as anteriores. Essa tarefa, conforme Quadro 1 já apresentado neste artigo, rompe a sequência de comandos que guiavam a criança a levar Mimi para algum lugar, fazendo com que a criança precise levar algo de Mimi para o personagem humano.

A seguir, o Gráfico 3 apresenta por meio da mesma estrutura do Gráfico 2 as ocorrências da atenção conjunta composicional.

Gráfico 3 - Ocorrências de AC composicional

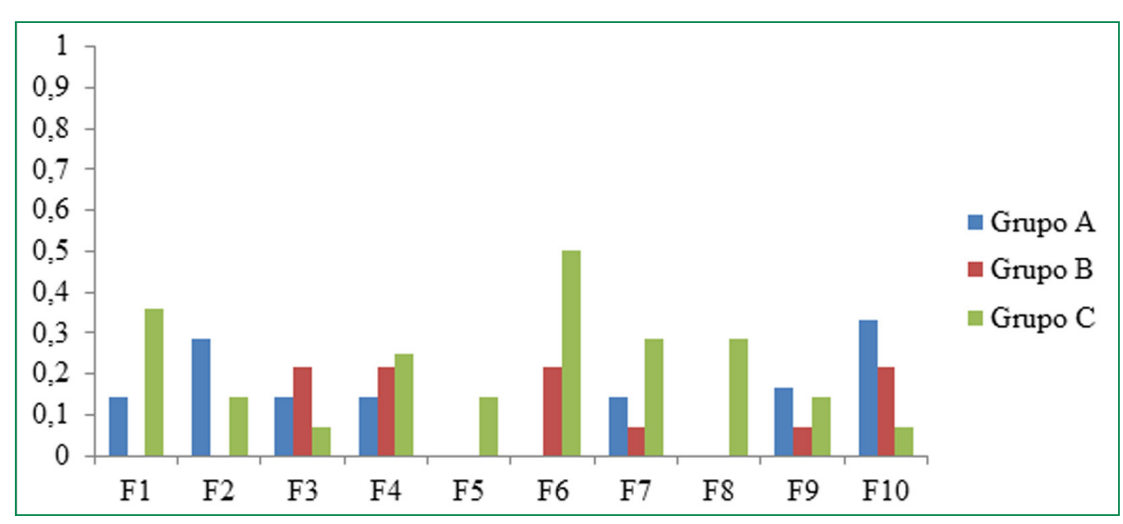

Fonte: Costa Filho (2016, p. 169) 
Ao contrário do que aponta o Gráfico 2 sobre o engajamento nas cenas de AC atual, o Gráfico 3 revela que o maior índice de ocorrências de $\mathrm{AC}$ composicional foi entre as crianças do grupo $\mathrm{C}$, que se engajaram neste processo interativo em todas as fases. Em seguida, o grupo A, com ocorrências em sete fases e, por fim, o grupo B, cujas crianças se engajaram na $\mathrm{AC}$ composicional em seis fases apenas.

Considerando que a AC composicional requer primeiramente o estabelecimento da atenção conjunta virtual, os dados referentes ao grupo C parecem ser justificados pelo fato de que foram as crianças deste grupo que demonstraram maior quantidade de interação com o interlocutor virtual quando jogaram com $\mathrm{Mimi}^{\odot}$. No entanto, a busca pelo interlocutor atual entre as crianças do grupo $C$ também pode demonstrar que para elas, embora com alta incidência de atenção conjunta virtual, a virtualidade proposta no jogo $\mathrm{Mimi}^{\odot}$ não parece capaz de prendê-las na interação por muito tempo, sendo necessário a estas crianças buscar um parceiro que na realidade atual volte também sua atenção para dentro da cena de atenção conjunta virtual.

Quanto ao grupo $\mathrm{A}$, à medida que as crianças deste grupo se engajam em um número superior de cenas de atenção conjunta atual e apresentam mais dificuldade em se engajar na atenção conjunta virtual, os dados que quantificam a AC composicional podem ser vistos como surpreendentes, já que seria bem aceitável (e até esperado) uma incidência menor que em comparação à contabilizada. Isso porque, como já mencionamos, para que haja a AC composicional, primeiro a criança precisa se engajar na atenção conjunta virtual. Por outro lado, é também por meio das numerosas cenas de atenção conjunta atual com a professora que a criança passa a estabelecer mais cenas de atenção conjunta virtual. Ou seja, por estar ancorada no formato de AC atual, a AC composicional é estabelecida entre as crianças do grupo $\mathrm{A}$, já que o interlocutor atual conduz às crianças deste grupo à interação com o virtual. $\mathrm{O}$ papel da professora, portanto, ilustra a forma a ação colaborativa, discutida por Tomasello e Carpenter (2007), constitui-se como elemento integrante do processo de atenção conjunta.

O grupo B, por sua vez, quase tem o mesmo número de cenas de atenção conjunta composicional que o grupo A. Para esse grupo, parece haver uma distinção mais estabelecida entre as cenas de atenção conjunta atual e virtual, já que demonstram um número elevado de atenção conjunta tanto com o interlocutor atual, quanto com o virtual. Em outras palavras, por ainda recorrerem bastante ao interlocutor atual e por apresentarem habilidades cognitivas acerca do processo de atenção conjunta que dão suporte para que se engajem em um elevado número de cenas de atenção conjunta virtual, as crianças do grupo B apresentam uma quantidade de atenção conjunta composicional que permite a este processo ser visto como o meio do caminho entre o atual e o virtual, ou a mescla das duas realidades.

Para finalizar a discussão acerca das ocorrências das cenas de atenção conjunta com a professora, analisaremos os Gráficos 4 e 5 que mostram mais uma vez o quantitativo de cenas de atenção conjunta atual e composicional, porém, sob o ângulo das duas jogadas que as crianças realizaram com $\mathrm{Mimi}^{\odot}$. O objetivo dessa abordagem foi verificar se houve diferença na quantidade de vezes em que as crianças buscaram a professora entre a primeira e a segunda jogada, considerando que esta aconteceu com as crianças já conhecendo a estrutura do jogo.

Comparando os Cráficos 4 e 5, podemos notar que o quantitativo de ocorrências de AC atual entre criança e adulto (professora) segue, de fato, em ordem decrescente do grupo A para o grupo C. Esse comportamento numérico é visto em ambas as jogadas 1 e 2, porém, o número de ocorrências de AC atual é maior durante a jogada 1 , o que mais uma vez ratifica a ideia de que o modelo de atenção conjunta com o interlocutor atual tende a ser mais utilizado pelas crianças que ainda não imergiram no contexto oferecido pela realidade virtual. 
Gráfico 4 - Ocorrências de atenção conjunta com o interlocutor atual (jogada 1)

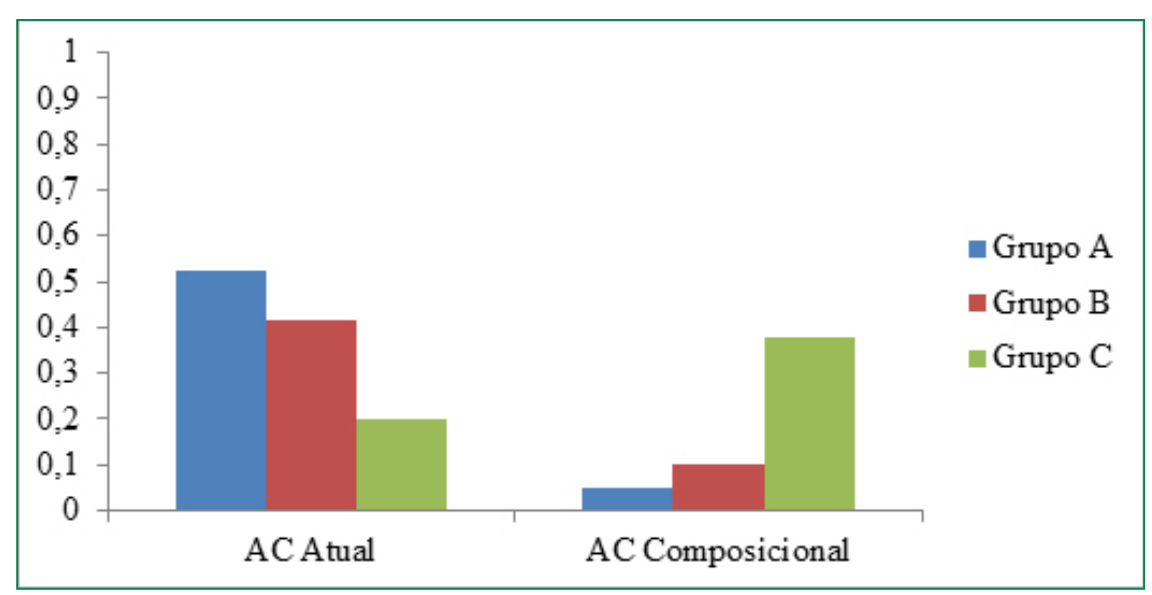

Fonte: Costa Filho (2016, p. 171)

Gráfico 5 - Ocorrências de atenção conjunta com o interlocutor atual (jogada 2)

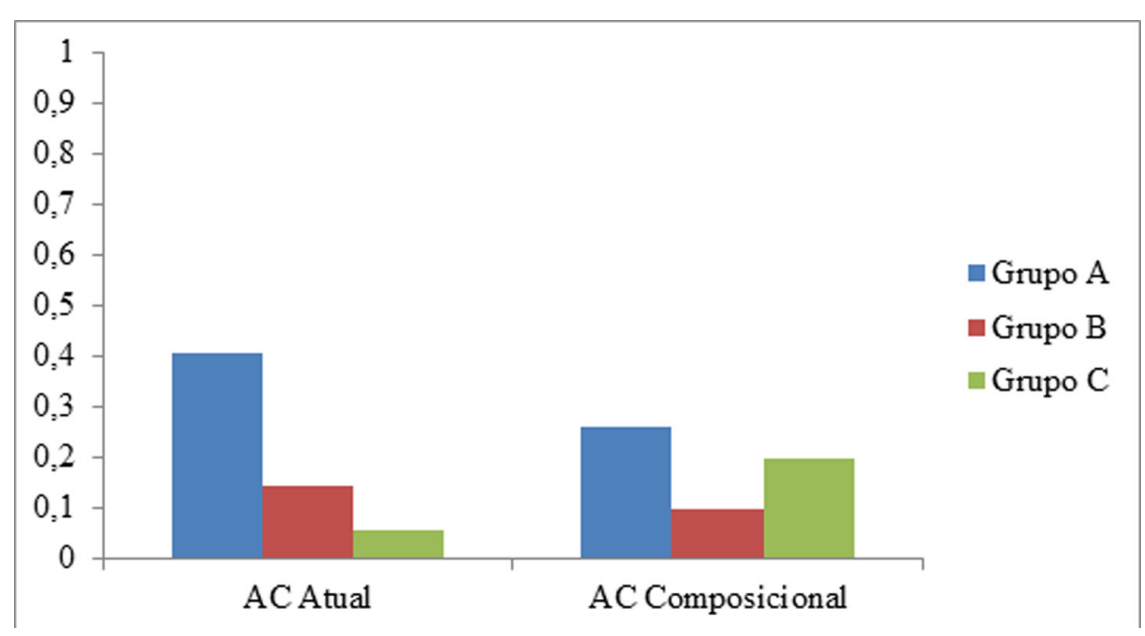

Fonte: Costa Filho (2016, p. 171)
A diferença no número de ocorrências entre os grupos também reforça a ideia trazida no parágrafo anterior. Isso porque as crianças que compõem o grupo A apresentam mais dificuldade em se engajar na interação virtual, enquanto as crianças do grupo C são as que demonstram mais facilidade em estabelecer este tipo de interação. Logo, podemos presumir que, quanto mais difícil for para a criança entrar na interação com o interlocutor virtual, mais chances há de que ela busque estabelecer a atenção conjunta com o interlocutor atual. Essa busca, por sua vez, pode ser ainda uma consequência da não atenção conjunta virtual, uma vez que se a criança não se engaja na interação virtual, dificilmente compreenderá a tarefa solicitada pelo jogo Mimi@ , reforçando, então, a necessidade de a professora intervir e participar da ação colaborativa reapresentando à criança os comandos já descritos pelo narrador.

A diminuição na quantidade de cenas de atenção conjunta atual da primeira para a segunda jogada provavelmente está associada ao fato de que, quando jogam a segunda vez, as crianças já possuem um conhecimento maior sobre a estrutura e sobre as tarefas que serão propostas em $\mathrm{Mimi}^{\odot}{ }^{\oplus}$. Destacando, entretanto, o conhecimento sobre o jogo, vimos que este é adquirido com a repetição dos cenários e do funcionamento das fases que têm por objetivo central realizar tarefas que representam os cuidados com o gatinho Mimi. Além disso, podemos notar que já ao longo da primeira jogada as crianças demonstram, ainda que não nas primeiras fases, dirigir e manter a atenção em volta do jogo $\mathrm{Mimi}^{\odot}{ }^{\odot}$. Por estarem, então, em atenção conjunta acerca da narrativa do jogo, os usuários acabam por coletar as informações que serão úteis não apenas para as fases seguintes, mas, principalmente, para a segunda jogada, que nada mais é que uma repetição do que foi feito ao longo da primeira.

Corroborando e ultrapassando o que trazem Bruner $(1975$; 1983) e Tomasello (2003), percebemos que o processo de atenção conjunta não somente garante o lugar da criança na troca interativa no período em que ela 
ainda não detém as estruturas verbais da língua, mas também se constitui como um funcionamento primordial para a aprendizagem pela criança, já que é na atenção conjunta que novas informações podem ser armazenadas. Isso fornece, pois, evidências de que a atenção conjunta não é importante apenas para as crianças que ainda não adquiriram linguagem, mas também para crianças - ou até mesmo para adultos - que estejam submetidas a contextos de aprendizagem em geral.

Retomando os Gráficos 4 e 5, percebemos que durante a primeira jogada o número de ocorrências de AC composicional é inversamente proporcional ao das ocorrências de $\mathrm{AC}$ atual, ou seja, enquanto o grupo $\mathrm{C}$ demonstra a maior quantidade, o grupo A é o que menos se engaja no processo composicional mesclando a interação com os interlocutores atual e virtual. Durante a segunda jogada, no entanto, o número se modifica e o grupo A apresenta um considerável aumento nas cenas de AC composicional, chegando a ultrapassar o quantitativo apresentado pelo grupo C. Já o grupo B mantém o mesmo número de ocorrências de $\mathrm{AC}$ composicional apresentado durante a jogada 1.

A diferença apresentada nos grupos $\mathrm{A}$ e $\mathrm{C}$ durante a segunda jogada parece destacar o fato de que, enquanto o grupo A demonstra conseguir estabelecer mais vezes um processo de atenção conjunta que já envolve o interlocutor virtual, o grupo C, cujas ocorrências de AC composicional diminuem, demonstra que precisa cada vez menos da intervenção do interlocutor atual para realizar as tarefas. Nesse sentido, as crianças que compõem o grupo C começam a estabelecer um número cada vez maior de cenas de atenção conjunta virtual, em que realizam as ações propostas em $\mathrm{Mimi}^{\odot}$ apenas com base na interação com o narrador, situado na realidade virtual.

Percebemos, por fim, que a transição da a AC atual para a AC virtual tem como processo intermediário a AC composicional, como se as interações com o interlocutor atual servissem de andaimes (WOOD; BRUNER; ROSS, 1976) para o estabelecimento da atenção conjunta virtual. Esse fato é corroborado pelos dados referentes às crianças do grupo $\mathrm{A}$, em que percebemos que da primeira para a segunda jogada, enquanto o formato de AC atual diminui, o de AC composicional aumenta.

Destacados os dados presentes no artigo, a seguir trazemos algumas considerações sobre a pesquisa.

\section{Algumas considerações e possibilidades}

Os dados de atenção conjunta virtual que analisamos neste artigo revelam o elemento mais importante para que este processo se desenvolva: o engajamento. Esse engajamento permite que a criança entre na atenção conjunta por meio da ação colaborativa. No caso da atenção conjunta virtual, a colaboração envolve a criança e os sujeitos na realidade virtual mantendo a atenção sobre um determinando objeto, e agindo para resolver uma tarefa dentro da própria realidade virtual. De um lado oposto, a atenção conjunta atual envolve a criança e a professora engajadas em resolver uma tarefa presente na realidade atual que requer uma ação sobre a realidade virtual. Em outras palavras, quando a atenção conjunta envolve apenas os sujeitos da realidade atual, o jogo (que representa o virtual) torna-se um objeto inserido na ação conjunta que acontece entre a criança e a professora, tomada como interlocutor pela criança que não tinha estabelecido a atenção conjunta virtual ou que buscava uma confirmação para a ação desempenhada na realidade virtual. No meio, entre a atenção conjunta atual e virtual, está o que chamamos de atenção conjunta composicional, em serve de transição entre os dois processos, como âncora - nos casos em que a criança não desenvolve atenção conjunta virtual e precisa da instrução da professora para realizar a tarefa proposta no jogo -, ou como complemento - quando a criança, após desempenhar a tarefa proposta no jogo, busca a professora para que ela entre na cena de atenção conjunta e confirme seu acerto. 
Vimos, pois, que as crianças mais novas tendem a desenvolver um maior número de cenas de atenção conjunta atual, que é um processo já estabilizado na rotina infantil desde o primeiro ano de vida. Mas não é apenas a capacidade de manutenção de atenção conjunta virtual que conta para que as crianças mais jovens recorram mais ao interlocutor atual. Conhecimento prévio sobre como jogar no tablet e, ainda - e talvez principalmente - conhecimento linguístico estão entre os fatores que influenciam a manutenção da atenção conjunta virtual e a ação colaborativa. Isso porque, de modo geral, as crianças do grupo A (22 a 36 meses) possuem um conhecimento linguístico inferior ao das crianças do grupo B (37 a 51 meses), as quais, por sua vez, possivelmente, têm menor domínio linguístico que as crianças do grupo C (52 a 65 meses). Sendo assim, uma vez que se depara com instruções transmitidas na fala de um interlocutor assíncrono, a criança que não compreende o comando tende a buscar um interlocutor que possa agir sincronicamente para que ela se engaje na cena de atenção conjunta e cumpra a tarefa do jogo.

Esses dados revelam, portanto, para além da constituição da atenção conjunta virtual e de sua relação com a ação colaborativa. Dada a importância do envolvimento conjunto para a realização das tarefas do jogo, quer seja com o narrador ou com a professora, percebemos que a atenção conjunta é um processo que acompanha a criança desde seu primeiro ano de vida e se faz presente não somente na fase de aquisição inicial da linguagem, mas principalmente na consolidação da linguagem, por meio de usos linguísticos e contextos diversos, perpassando processos como o da construção da referência linguística, para o qual a atenção conjunta é fundamental.

É exatamente por esse 'valor' fundamental que a atenção conjunta possui para a consolidação da referência linguística que percebemos a necessidade de aprofundamento de pesquisas sobre o tema, não apenas como mera interação entre sujeitos, mas como lócus por meio do qual possam ser observados os mais variados usos e fenômenos linguísticos na fala da criança.

\section{Referências}

BRUNER, Jerome. Childs Talk: Learning to use language. New York: Norton, 1983. From communication to language: a psychological perspective. Cognition, v. 3, n. 3, p. 255-287, 1975.

COSTA FILHO, José Moacir Soares da. Atenção conjunta: o jogo da referência na realidade virtual. 2016. 215f. Tese (Doutorado em Linguística) - Universidade Federal da Paraíba, João Pessoa, 2016.

EILAN, Naomi. Joint attention, communication and mind. In: EILAN, Naomi et al. $i$ : communication and other minds. Oxford: OUP, 2005. p.1-33.

GÓMEZ, Juan-Carlos. Joint attention and the notion of subject: insights from apes, normal children, and children with autism. In: EILAN, Naomi et al. Joint Attention: communication and other minds. Oxford: OUP, 2005, p. 65-84.

LÉVY, Pierre. O que é o virtual? Tradução de Paulo Neves. 2. ed. São Paulo: Editora 34, [1956] 2011.

MIGUENS, Sofia. Conceito de crença, triangulações e atenção conjunta. In: MIGUENS, Sofia; MAURO, Carlos. E. E. (Ed.). Perspectives on Rationality. Porto: Universidade do Porto, Faculdade de Letras, 2006. p.99-117.

MELO, Glória Maria Leitão de. Cenas de atenção conjunta entre professoras e crianças em processo de aquisição da linguagem. 2015. 227 f. Tese (Doutorado em Linguística) Universidade Federal da Paraíba, João Pessoa, 2015.

PEACOCKE, Christopher. Joint attention: its nature, reflexivity and relation to common knowledge. In: EILAN, Naomi et al. Joint Attention: communication and other minds. Oxford: Oxford University Press, 2005. p. 298-324.

TOMASELLO, Michael. Origens culturais da aquisição do conhecimento humano. Tradução de Cláudia Berliner. São Paulo: Martins Fontes, 2003.

TOMASELLO, Michael; CARPENTER, Melinda. Shared intentionality. Developmental science, v. 10, n. 1, p. 121-125, 2007.

WOOD, David; BRUNER, Jerome; ROSS, Gail. The role of tutoring in problem solving. Journal of Child Psychology and Psychiatry, v. 17, n. 2. p. 89-100, 1976.

Recebido em 24/01/2017.

Aceito em $07 / 08 / 2017$ 